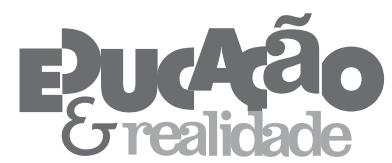

\title{
Alteridade e Adolescência: uma contribuição da psicanálise para a educação
}

\author{
Eliane Gomes dos Santos' \\ Maria da Gloria Schwab Sadala' \\ 'Universidade Veiga de Almeida (UVA), Rio de Janeiro/RJ - Brasil
}

RESUMO - Alteridade e Adolescência: uma contribuição da psicanálise para a educação. Pretendemos com este artigo contribuir para o campo da Educação, utilizando algumas formulações teóricas da Psicanálise referentes à alteridade e à adolescência. O tema da alteridade é fundamental nas investigações e práticas tanto da Educação como da Psicanálise, principalmente se considerarmos os processos psíquicos, próprios da adolescência, que envolvem importantes elaborações relacionadas à questão da alteridade. As articulações propostas neste artigo poderão contribuir significativamente para a prática dos educadores em geral, em especial, com adolescentes, esclarecendo a importância da alteridade e seu papel na adolescência. Palavras-chave: Alteridade. Adolescência. Educação. Psicanálise.

ABSTRACT - Otherness and Adolescence: a psychoanalytic contribution to education. This article aims to contribute to the field of education, using some psychoanalytic theoretical formulations related to otherness and adolescence. The theme of otherness is fundamental in both education and psychoanalysis as far as practice and research are concerned, especially in the realm of the psychic processes at play in adolescence, which involve important elaborations related to the issue of otherness. The proposed articulations in this article will make a significant contribution to the practice of educators, as a whole, and especially those working with teenagers, thus enhancing the importance of otherness and its role in adolescence. Keywords: Otherness. Adolescence. Education. Psychoanalysis.

Educação \& Realidade, Porto Alegre, v. 38, n. 2, p. 555-568, abr./jun. 2013. 555

Disponível em: <http://www.ufrgs.br/edu_realidade> 
Alteridade e Adolescência

\section{Introdução}

A questão da alteridade atravessa a teoria psicanalítica desde as primeiras formulações freudianas até a obra de Lacan, na qual encontramos tematizações específicas, apontando para a ideia de que não há sujeito sem outro.

Com a descoberta do inconsciente, Freud revolucionou as concepções a respeito da subjetividade, afirmando que o eu não é senhor em sua própria casa. Por outro lado, Lacan apontou a impossibilidade de um eu unificado, demonstrando através de suas elaborações sobre o estádio do espelho, que o eu é, essencialmente, outro.

A alteridade descoberta por Freud retirou o sujeito do centro do psiquismo, tal como Copérnico afastou a ideia da terra como centro do universo. De determinante, o sujeito passa ao lugar de determinado, em função do funcionamento da Outra cena, do Outro do inconsciente.

O tema alteridade é de fundamental importância nas investigações e nas práticas do campo da Educação, principalmente se considerarmos este momento da vida nomeado como adolescência, no qual se sucedem significativas elaborações relacionadas à questão da alteridade. Além disso, no mundo contemporâneo, o social impõe padronizações de ordem tecnológica, econômica e política, adicionando maior complexidade a um contexto já tão complexo como é o da educação com adolescentes. Tensões nas relações familiares, escolares e socioculturais são observadas, e a Educação coloca-se, por vezes, num lugar de reflexão e mediação, principalmente por meio da escola e seus educadores, tentando gerenciar conflitos e permitindo compreender diferenças para uma vida social mais satisfatória.

A adolescência é considerada pela psicanálise como um processo crucial na construção da subjetividade. Implica num trabalho subjetivo que envolve o re-conhecimento do corpo, das relações familiares e sociais, das possibilidades de ação no contexto social, e tudo isto conduz o adolescente a um reposicionamento em relação à alteridade.

Acreditamos que as formulações teórico-clínicas da Psicanálise, que articulam as concepções a respeito de alteridade e adolescência, poderão contribuir significativamente para o campo da Educação, esclarecendo os processos psíquicos próprios do funcionamento do sujeito adolescente, assim como a função primordial da alteridade em relação à subjetividade.

Observamos que a interlocução entre Psicanálise e Educação data de longo tempo. Freud ressaltou o lugar dos filhos como prolongamento do narcisismo dos pais e também evidenciou a possibilidade dos mestres funcionarem como catalizadores dos desejos incestuosos e seus efeitos remanescentes do período da infância.

A possibilidade de se tomar a Psicanálise como eixo articulador entre diferentes áreas do saber se deve a sua natureza interdisciplinar. A própria criação deste novo saber com Freud ocorreu através de arti-

556 Educação \& Realidade, Porto Alegre, v. 38, n. 2, p. 555-568, abr./jun. 2013. Disponível em: <http://www.ufrgs.br/edu_realidade> 
culações com outras ciências como a Neurologia, Psiquiatria e, em seu desenvolvimento, outros saberes foram convocados, tais como a Filosofia, a Antropologia, a Educação, a Linguística, a Lógica, etc.

No presente trabalho, pretendemos dar continuidade a essa prática interdisciplinar tão presente na Psicanálise, retomando a questão da alteridade e da adolescência à luz da teoria psicanalítica com o objetivo de contribuir para os educadores em sua prática com adolescentes.

\section{Alteridade e Constituição do Sujeito}

As elaborações teóricas do campo da Psicanálise - que envolvem concepções a respeito do inconsciente, desejo, transferência, adolescência e outras - evidenciam que a alteridade ocupa um lugar de fundamental importância na constituição da subjetividade. Consideramos necessário, de início, esclarecer duas modalidades de alteridade que são importantes na articulação proposta neste trabalho: o pequeno outro(a) e o grande Outro(A). Trata-se de construções teóricas do psicanalista francês Jacques Lacan. As letras a e A referem-se aos termos da língua francesa autre e Autre, respectivamente.

O pequeno outro(a) refere-se ao semelhante, tratado como igual e rival, carreando a marca do estádio do espelho tal como formulado por Lacan a partir de sua leitura do texto freudiano a respeito do narcisismo. Pertence ao registro do imaginário, registro do sentido e da consciência, o qual através do mecanismo da identificação com o outro faz surgir a crença em um eu. $\mathrm{O}$ eu está condenado à alienação a seu outro ideal, justamente por se constituir pela imagem do outro. O sujeito percebe o eu como outro e por isso dizemos que o eu é o outro para o sujeito do inconsciente, ou seja, para o desejo. Lacan estabeleceu a notação a-a' para esse eixo entre o eu e o outro, a qual aparece no conhecido esquema $L$ através do eixo imaginário. Neste esquema, a' representa os objetos do sujeito e a representa o eu. É importante notar que o eixo imaginário funciona como anteparo para o Outro do inconsciente.

\section{Figura 1 - Esquema L}

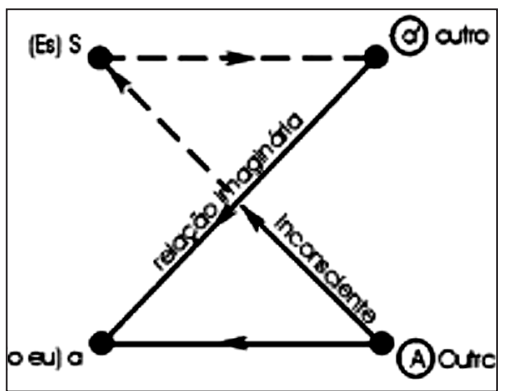

Lacan escreve o matema i(a) para representar que o outro é o eu, pois o outro é o eu ideal, ou seja, imagem proveniente dos significantes do Outro, significantes que constituem o Ideal do eu que podemos ler 
como Ideal do Outro e por isso escritos por Lacan através do matema I(A). Durante boa parte da vida, na melhor das hipóteses, o sujeito tentará igualar seu eu ao eu ideal veiculado pelas pessoas importantes de sua vida. É desta forma que o desejo do Outro é veiculado na subjetividade.

Em suas formulações sobre o imaginário Lacan sempre incluiu a função do simbólico, e no estádio do espelho está presente o olhar daquele que ocupa o lugar do Outro. Concluímos, assim, que junto ao imaginário situa-se também o grande Outro, simbólico, cujo discurso constitui o inconsciente. O grande Outro é considerado um lugar e representa a alteridade para o eu consciente. Dele são provenientes as determinações simbólicas relacionadas à história do sujeito e funciona como um arquivo das palavras dos outros considerados importantes pelo sujeito desde a sua infância. Este Outro determina os atos do sujeito, desde seu pensamento até sua ação e, por esta razão, o eu não pode ser senhor em sua própria casa.

\section{Afirmamos com Quinet:}

O “eu” está para o outro assim como o "sujeito" está para o Outro. O sujeito é determinado pelos significantes do Outro. A identidade - que é imaginária - do eu vem do outro; mas o sujeito é sem identidade (Quinet 2012, p. 22).

Há significantes do Outro que se impõem ao sujeito e aos quais ele se identifica, agindo numa conformidade com eles, tal como numa ordem a cumprir. A esta modalidade de operação do sujeito com os significantes provenientes de A, Lacan dá o nome de alienação. É, de início, uma operação necessária, já que o desejo é, por origem, desejo do Outro. No entanto, é possível o sujeito se desalienar do Outro através da operação de separação, na qual o sujeito, ao descobrir esses significantes-mestres que o determinam, abre para si a possibilidade de modificar sua experiência subjetiva. O sujeito se constitui nesta oscilação entre a alienação e a separação no que diz respeito ao Outro.

Na visão da Psicanálise, o processo da adolescência implica, justamente, num incremento de desalienação, possibilitando a efetividade da operação de separação. O fato do Outro do inconsciente estar sempre presente na relação do sujeito com o outro, seu semelhante, o trabalho psíquico do sujeito adolescente torna-se ainda mais complexo, pois a operação de separação incidirá sobre aqueles que foram ou ainda são seus objetos de amor, ainda funcionando como suporte no enfrentamento do desamparo fundamental.

É por meio dos semelhantes com quem convivemos - primeiramente nossos pais, depois nossos mestres - que o desejo encontra as vias possíveis para sua circulação, travestindo-se de diferentes demandas dirigidas ao sujeito.

Na introdução de seu texto Psicologia das Massas e Análise do Eu (1921), afirma Freud: 
A oposição entre psicologia individual e psicologia social ou das massas, que a primeira vista talvez nos pareça muito substancial, perde boa parte de sua nitidez se é considerada mais a fundo. É verdade que a psicologia individual se refere ao ser humano singular e estuda os caminhos pelos quais busca alcançar a satisfação de suas moções pulsionais. Porém, só raramente, sob determinadas condições de exceção, pode prescindir dos vínculos com os outros. Na vida anímica do indivíduo, o outro conta, com total regularidade, como modelo, como objeto, como auxiliar e como inimigo, e por isso desde o início mesmo, a psicologia individual é simultaneamente psicologia social neste sentido mais lato, porém inteiramente legítimo (Freud, 1984, p. 67).

O enlaçamento do sujeito com o Outro é traduzido de vários modos nas diversas relações humanas: familiares, amorosas e profissionais. A história do sujeito é uma história com a alteridade, sempre complexa, provocando efeitos de sofrimento, amor, inveja, ciúme e competição.

A alteridade é fundamental, responde pela constituição do sujeito, sendo o ponto de origem do desejo. São as palavras provenientes do campo da linguagem que constituem a matéria-prima para a formação do inconsciente, portanto, vem do Outro a determinação do destino do sujeito.

Evoquemos o que a psicanálise nos ensina sobre o campo da linguagem, a função da fala e sua importância na relação do sujeito com a alteridade.

Em seu texto A Interpretação das Afasias (1891), Freud compara o aparelho psíquico a um aparelho de linguagem para tratar da constituição do sujeito. Podemos pensar que esta ideia freudiana antecipa a formulação lacaniana que concebe o sujeito como efeito do significante. Podemos dizer que são as palavras provenientes do campo do Outro que irão constituir o inconsciente.

Lacan afirma:

Não é estranho à essência da palavra, se é que se pode dizer isso, o agarrar-se ao outro. A palavra é mediação sem dúvida, mediação entre o sujeito e o outro, e ela implica na realização do outro na mediação mesma. Um elemento essencial da realização do outro é que a palavra possa nos unir a ele (Lacan, 1986, p. 61).

Conforme dito anteriormente, para a psicanálise o sujeito é efeito da ordem simbólica. Isto porque o sujeito é consequência do significante que é regido pelas leis do simbólico.

O sujeito do inconsciente testemunha a dependência do falante à ordem simbólica que preexiste à sua constituição. Este sujeito de que se trata no campo da Psicanálise é descentrado, acéfalo, dividido, evanescente.

Educação \& Realidade, Porto Alegre, v. 38, n. 2, p. 555-568, abr./jun. 2013

Disponível em: <http://www.ufrgs.br/edu_realidade> 
Alteridade e Adolescência

O conceito de sujeito na Psicanálise foi introduzido por Lacan a partir das elaborações freudianas em torno da descoberta do inconsciente. Embora Freud nunca tenha usado a palavra sujeito em suas referências ao inconsciente, reconhece-se que o conceito de inconsciente freudiano está extremamente próximo do conceito de sujeito lacaniano.

Sabemos que o sujeito da Psicanálise não é natural, ao contrário, é construído passo a passo, sempre por meio da relação com outro aparelho de linguagem.

O inconsciente é marcado pela inscrição do significante. E o assujeitamento à ordem significante aponta para o que a psicanálise lacaniana afirma: inconsciente e linguagem têm a mesma estrutura, ou ainda, o inconsciente funciona como uma linguagem.

O desejo é estruturado pela via da fala e as palavras permitem a circulação do desejo. A necessidade do bebê interpretada pela mãe inscreve-o no universo da linguagem.

Lacan pensa que uma das vertentes do desejo é que o sujeito procura, inicialmente, constituir-se em objeto de desejo do seu semelhante, em primeira instância, a mãe.

No texto freudiano intitulado Projeto de uma Psicologia (1895), Freud já vinculava suas descobertas sobre o inconsciente à satisfação pulsional nas relações do sujeito com o próximo:

Um outro ser humano [...] semelhante foi, ao mesmo tempo, o primeiro objeto de satisfação, o primeiro objeto hostil e também sua única força auxiliar. É por esse motivo que é em seus semelhantes que o ser humano aprende a se re-conhecer (Freud, 1976, p. 438)

A primeira apreensão da realidade pelo sujeito é através do que Freud denomina Nebenmensch, onde neben = próximo e mensch $=$ homem. É a partir do próximo que Freud articula a função da alteridade. O sujeito, na sua relação com a realidade, vai ao encontro do objeto que é, desde sempre, perdido. Vai à procura daquilo que é impossível de ser achado: das Ding - o Outro absoluto - a mãe.

A lei de proibição do incesto determina a inacessibilidade da mãe. É o que está no fundamento de das Dingl. Freud designará posteriormente como interdição do incesto o princípio da lei primordial, mola de todos os desenvolvimentos culturais e, ao mesmo tempo, identifica o incesto como o desejo mais fundamental, o desejo do filho pela mãe. Só há desejo porque o objeto é interditado e inatingível.

O desejo pela mãe não poderia ser satisfeito, pois representaria o fim da demanda e do inconsciente. A mãe ocupa o lugar da Coisa como impossível no inconsciente.

Esta primeira experiência inscreve o sujeito no campo do desejo. Diante da falta de objeto, são investidos, simultaneamente, os traços da experiência de satisfação e é daí que o desejo emerge, presentificando a dimensão de perda e o retorno a uma satisfação já experimentada. 
Lacan coloca a Coisa no centro e, em volta dela, o mundo subjetivo do inconsciente estruturado nas cadeias significantes, mas destaca a dificuldade de sua representação topológica: está no centro, mas no sentido de estar excluída.

A noção de das Ding formulada por Freud no texto Projeto de uma Psicologia (1895) presentifica uma divisão constitutiva no campo do Outro e, portanto, no sujeito. Lacan retoma esta ideia para elaborar a noção de desejo.

A Coisa situa-se em um nível além do universo da linguagem, fora do espaço da representação, definindo-se como ausente, como realidade muda que regula a trama significante e o caminho do sujeito em relação ao mundo do desejo. Referindo-se ao texto de Freud de 1925 A Denegação, Lacan identifica das Ding à tendência a retornar que caracteriza a orientação do sujeito em direção ao objeto. O encontro do objeto, como Freud afirma em vários textos, é sempre um reencontro, uma vez que o objeto absoluto do desejo não existe. O que se reencontra está irremediavelmente a uma certa distância da Coisa, o que impõe o caminho da repetição. Como Outro absoluto do sujeito, das Ding não é reencontrada, mas apenas há sinais de suas coordenadas de prazer.

Das Ding não pertence, portanto, ao espaço da representação, não habita naquilo que Freud chamou de aparato psíquico, mas nem por isso deixa de aparecer embora esteja ausente. Algo no nível das Vorstellungen (ou dos significantes) sinaliza a Coisa.

Esse algo não é uma coisa, nem a própria Coisa disfarçada, mas um vazio que não pode ser preenchido adequadamente por objeto algum. É o que Lacan denomina objeto a. Não se trata de um objeto específico, mas é um vazio, um furo. Lacan, ao se referir ao objeto a como furo, aponta sua condição de perdido para sempre. O objeto a não é o objeto de desejo, mas o objeto causa de desejo.

Lacan estuda a temática do desejo em vários trabalhos, destacando-se, especialmente, O Seminário, livro 5: as formações do inconsciente (1957-1958) e O Seminário, livro 6: o desejo e sua interpretação (1958-1959). Demonstra que uma das vertentes do desejo está na busca inicial do sujeito para se constituir como objeto de desejo da mãe. É a mãe quem interpreta as necessidades do bebê, inscrevendo-o, assim, no universo da linguagem. A linguagem confere ao desejo uma de suas características essenciais: o deslocamento metonímico infinito de um para outro objeto. O desejo é estruturado pela via da fala e desejamos porque falamos. Portanto, a linguagem é a estrutura que nos torna desejantes. O desejo fica, ao mesmo tempo, inscrito e oculto na demanda. Na realidade, o que sempre se demanda é ser amado, e uma ferida narcísica pode surgir diante da frustração da demanda. Podemos tolerar muitas coisas, mas não suportamos não sermos reconhecidos e amados.

O desejo não poderá jamais ser nomeado e circulará metonimicamente, de um para outro significante, no âmbito da relação do su-

Educação \& Realidade, Porto Alegre, v. 38, n. 2, p. 555-568, abr./jun. 2013. 561

Disponível em: <http://www.ufrgs.br/edu_realidade> 
Alteridade e Adolescência

jeito com a alteridade. Como a estrutura obriga o contínuo movimento do desejo, na adolescência continuamos a tratar do sujeito do desejo. Apresentaremos, a seguir, algumas considerações a respeito do sujeito adolescente.

\section{O Sujeito Adolescente}

A Psicanálise atribui estatuto de sujeito ao adolescente, considerando-o sujeito do desejo, desejo que lhe é próprio, particular, intransferível. Este desejo não é necessariamente equivalente ao dos pais, escola ou sociedade.

Observamos que a adolescência não é uma categoria surgida no campo da Psicanálise. Este termo nasceu no final do século XVIII e início do século XIX, a partir da necessidade social para designar uma certa faixa etária, a fim de integrá-la na sociedade e deste modo exercer melhor vigilância. A adolescência surgiu com um contorno preciso, e no século XIX passou a ser reconhecida como um momento crítico na vida, como fase de riscos potenciais para si próprio e para a sociedade, uma vez que turbulência e contestação foram as principais referências à adolescência.

O século XX foi denominado o século da adolescência. Este período da vida assim nomeado se expandiu, empurrando a infância para trás e a idade adulta para frente. Cada vez mais cedo se desejava chegar à adolescência e cada vez mais tarde era deixada para trás.

A alegria de viver, o entusiasmo, o espírito de aventura, o idealismo tão presentes em tantos adolescentes, fizeram deles um foco da mídia, um polo de irradiação da moda. Estiveram presentes em importantes mobilizações sociais e várias lutas foram empreendidas na tentativa de introduzir algo novo na cultura: juventude transviada, movimento hippie, movimentos políticos universitários. Sabemos que os jovens dos anos 1960 passaram a negar todas as manifestações da sociedade de consumo. Essas observações nos levam a pensar em transformações da relação do sujeito adolescente com a alteridade. Lembramos que, em psicanálise, sempre que falamos de sujeito, trata-se do sujeito do desejo e a adolescência é um momento de importância fundamental na constituição da subjetividade.

Freud não faz diferença entre adolescência e puberdade. Engloba neste último termo, as transformações corporais e psíquicas deste período da vida. Em seu texto Três Ensaios sobre a Sexualidade (1905) aponta como o trabalho psíquico mais importante, e doloroso, desta época da puberdade o desligamento da autoridade dos pais, o qual é imprescindível para a evolução cultural, dando, ao mesmo tempo, um certo caráter de crise na adolescência.

Se considerarmos o adolescente como o sujeito que se confronta, simultaneamente, com o real do sexo e a responsabilidade do ato, podemos analisar a questão da alteridade na adolescência a partir desta conjunção. 
Este novo encontro com o real do sexo apresenta ao adolescente uma nova questão relativa à alteridade: o outro sexo. Isto demanda ao adolescente dois posicionamentos, aquele que se refere à sua posição sexual como homem ou mulher, e outro, que diz respeito a uma nova escolha de objeto. É na adolescência que o objeto sexual revela-se, desde o início, como inadequado à completude, impondo-se ao adolescente um trabalho de luto pela perda da ilusão da completude, verificada, então, como impossível. Gradativamente, coloca-se para ele a ideia de que há um vazio que não pode ser preenchido definitivamente por objeto algum. Isto porque, como dito anteriormente neste trabalho, o objeto está perdido para sempre.

Assumir a responsabilidade de seus atos só se torna possível quando o sujeito adolescente efetua, suficientemente, o desligamento da autoridade dos pais. Evocamos aqui o que foi apresentado na parte inicial deste texto, intitulado Alteridade e a Constituição do sujeito. Se o sujeito se constitui a partir do campo do Outro, incorporando os significantes-mestres daí provenientes e que comandam os seus atos, com o despertar da adolescência, o sujeito poderá optar pela separação de tais significantes.

Podemos entender a operação psíquica própria da adolescência, nomeada por Freud como desligamento da autoridade dos pais, sob dois prismas:

- queda da imagem ideal dos pais

- culminância da operação de separação.

É fato que a passagem da infância à idade adulta exige um corte. Anterior à adolescência, situa-se um período nomeado por Freud como latência, por nele se constatar uma certa inibição das pulsões sexuais que impulsionaram as fantasias construídas no tempo da infância. Na adolescência, há o despertar dessas fantasias adormecidas, em concomitância com grandes revelações referentes ao sexo.

Em termos psicanalíticos, a adolescência é entendida como um trabalho psíquico de elaboração de perdas, elaboração da falta no Outro e elaboração de escolhas. Estas concepções estão todas fundamentadas na afirmativa freudiana que aponta o desligamento da autoridade dos pais como o principal, e mais doloroso, trabalho psíquico a ser realizado na adolescência.

A adolescência pode ser concebida como paralela à constituição de uma ética, quando o enfrentamento do desamparo passa a ser acompanhado da responsabilidade pelos seus próprios atos. Este momento especial da constituição do sujeito - a adolescência - implica em demitir o Outro de sua função salvadora.

Não se restringir a satisfazer às demandas e assumir-se como sujeito do desejo, corresponde ao atravessamento da adolescência. Sabemos que o desejo da mãe barrado permite o investimento do sujeito para além de seu meio familiar. 
Alteridade e Adolescência

A lei do desejo exige algo que a sustente, pois sua instauração destrói a ilusão da completude e retira do Outro o poder absoluto que lhe era atribuído até então. É a função paterna, o suporte da lei do desejo.

Sabemos que é necessário que a criança desde cedo acredite nos pais como super-heróis para que possa aprender tudo o que a vida exige em termos de regras, normas e hábitos. E a queda da imagem ideal dos pais, necessariamente, causa mal-estar no adolescente, impulsionando-o a buscar nas identificações com seus pares, assim como nos ideais coletivos, um alívio frente ao horror do encontro com a castração.

A adolescência reafirma, especialmente, duas das fontes permanentes de sofrimento para o homem, apontadas por Freud em 1930 no texto Mal-estar na Cultura: a fragilidade do corpo e as relações humanas.

Diante de seu corpo em transformação e dos mal-entendidos familiares causados pelo desligamento gradativo da autoridade dos pais, o adolescente sofre e muitas vezes se isola; faz inscrições no corpo, seja para marcar o que é seu, seja para conservar um pertencimento a algum grupo.

A adolescência é um retorno, mesmo que permita arranjos de novas constelações. Retorno à sexualidade infantil. Mas a travessia da adolescência é marcada pelo registro da desilusão com o Outro da infância.

O adolescente não possui todas as condições de enfrentar as dificuldades e hostilidades que a vida apresenta, mas passa a acreditar que seus atos poderão lhe propiciar um mundo melhor vivível para si. $\mathrm{O}$ adolescente, gradativamente, toma em suas próprias mãos a responsabilidade de seu ato. $\mathrm{O}$ ato requer autoria e autoridade; corresponde a um fazer, uma escolha, e dele decorre uma responsabilidade.

A Psicanálise explica o processo da adolescência, propiciandonos, ao mesmo tempo, ferramentas para analisar os fatores que levam um sujeito a se identificar com a adolescência sem efetivar o encontro com o outro sexo, nem tornar-se responsável por seus atos. Nesta medida, a psicanálise oferece contribuições significativas para a prática com adolescentes no campo da Educação.

\section{E a Educação?}

A Educação tende a conceber o sujeito sob o viés da cognição com extrema ênfase nos princípios relativos ao campo da Pedagogia. Supomos que a Educação estabelece suas ações e objetivos pautada na concepção do sujeito da ciência, sem levar em conta o sujeito do desejo, tal como considerado no campo da Psicanálise. Sendo assim, as demandas dos jovens não são suficientemente valorizadas e a construção da subjetividade não costuma ocupar um lugar prioritário na Educação.

A psicanálise propõe uma nova teoria do sujeito, uma vez que faz a disjunção entre o eu e o sujeito, introduzindo, a partir daí, ideias fun- 
damentais referentes à noção de alteridade. A importância da alteridade para a subjetividade já se encontra em Freud, mas foi Lacan quem ampliou a concepção de alteridade, concebendo-a em diversas modalidades e criando o conceito de Outro, como já exposto anteriormente neste artigo.

A partir da formulação do Outro do inconsciente, podemos pensar na diferenciação elaborada por Lacan a partir do linguista Benveniste, entre sujeito da enunciação e sujeito do enunciado. O primeiro é desconhecido pelo segundo. O sujeito da enunciação é recalcado e inconsciente, enquanto o sujeito do enunciado corresponde ao discurso manifesto. A Psicanálise visa o sujeito da enunciação a partir do sujeito do enunciado, evidenciando todos os semblantes, mal-entendidos, lapsos, esquecimentos que podem resultar do interjogo entre esses dois sujeitos. A divisão do sujeito que divorcia o enunciado da enunciação é causa de mal-estar. Portanto, é preciso que os educadores considerem o adolescente para além de seus ditos, lembrando que os enunciados não são suficientes para concluir, principalmente quando se constata que a adolescência é marcada por um mal-estar resultante do registro da falta, do desencontro e da desilusão. Da falta, porque na adolescência há o reconhecimento da castração e do desamparo fundamental. Do desencontro, pelo fato do adolescente constatar que o objeto sexual não propicia a satisfação completa. Da desilusão, por se deparar com a impossibilidade da completude e com a queda dos pais daquele lugar de onipotência e onisciência. Esse lugar imaginarizado dos pais, em alguns casos, pode vir a ser ocupado pelos mestres, como recurso do adolescente para ainda tentar permanecer na alienação.

Se, por um lado, há sofrimento pelas perdas e desilusões que a desalienação impõe, a autonomia consequente ao trabalho de separação permite ao sujeito adolescente ser autor de um desejo que visa seu próprio destino e não mais a satisfação das demandas dos pais. Concluindo que só tem a si próprio para enfrentar o desamparo que a vida impõe e o mal-estar dele decorrente, o adolescente pode assumir a posição de sujeito desejante, efetuando suas escolhas e responsabilizando-se pelos seus próprios atos (Sadala, 2008, p. 126).

O reconhecimento dos educadores em relação às transformações nas relações do sujeito adolescente com a alteridade pode levá-los a ocupar um lugar facilitador para a realização do trabalho psíquico peculiar a ser elaborado pelos sujeitos adolescentes.

As imposições do mundo global capitalista geraram um grande interesse pela noção de alteridade devido aos fatos cotidianos das relações sociais e culturais, cercados de tensões entre os diversos grupos. Na escola não é diferente, esses acontecimentos são reproduzidos afetando o contexto da Educação, sendo imprescindível ao professor entender e transmitir a noção de alteridade como forma de minimizar os conflitos gerados pelas diferenças.

Educação \& Realidade, Porto Alegre, v. 38, n. 2, p. 555-568, abr./jun. 2013.

Disponível em: <http://www.ufrgs.br/edu_realidade> 
Alteridade e Adolescência

A Psicanálise é constantemente convocada a se posicionar diante das questões colocadas pelos adolescentes, seus pais, escola e pela sociedade em geral. Situações como toxicodependência, suicídio, sexualidade, crise familiar e escolha profissional são, com frequência, associadas à adolescência.

Na XXXIV Conferência sobre Psicanálise, de 1933, Freud afirma:

E, ademais, devemos levar em conta o fato de que os objetos de nossa influência educacional têm disposições constitucionais inatas muito diferentes, de modo que é quase impossível que o mesmo método educativo possa ser uniformemente bom para todas as crianças (Freud, 1997, p. 182-183).

Freud sugere cuidado com a educação para todos. Propostas universais, padronizadas e uniformes não atendem ao grande alerta feito por Freud em relação à importância de se considerar a singularidade na Educação. Ele radicalizou suas concepções a respeito da Educação, inserindo-a na série das profissões impossíveis, ao lado das funções de governar e psicanalisar. No entanto, há educadores que argumentam sobre a possibilidade da ação do educador e dentre eles ressalta-se a concepção de Paulo Freire, indicando que a educação só se torna possível no contexto da relação do sujeito com a alteridade:

Ninguém educa ninguém, como tampouco ninguém se educa a si mesmo: os homens se educam em comunhão, mediatizados pelo mundo (Freire, 1981b, p. 79).

Para ressaltar a importância da consideração das diferenças na Educação, o teólogo e escritor Frei Betto apresenta reflexões a respeito da noção de alteridade:

O que é Alteridade?

É ser capaz de apreender o outro na plenitude da sua dignidade, dos seus direitos e, sobretudo, da sua diferença. Quanto menos alteridade existe nas relações pessoais e sociais, mais conflitos ocorrem. A nossa tendência é colonizar o outro, ou partir do princípio de que eu sei e ensino para ele. Ele não sabe. Eu sei melhor e sei mais do que ele. Toda a estrutura do ensino no Brasil, criticada pelo Professor Paulo Freire, é fundada nessa concepção. O professor ensina e o aluno aprende. É evidente que nós sabemos algumas coisas e, aqueles que não foram à escola, sabem outras tantas, e graças a essa complementação vivemos em sociedade. Numa sociedade como a brasileira em que o apartheid é tão arraigado, predomina a concepção de que aqueles que fazem serviço braçal não sabem. No entanto, nós que fomos formados como anjos barrocos da Bahia e de Minas, que só têm cabeça e não têm corpo, não sabemos o que fazer das mãos. Passamos anos na escola saímos com Ph.D., porém não sabemos cozinhar, costurar, trocar uma tomada ou um interruptor, identificar o 
defeito do automóvel... e nos consideramos eruditos. E o que é pior, não temos equilíbrio emocional para lidar com as relações de alteridade (Betto, 2012, online).

Na ótica freudiana, o homem está condenado a uma radicalidade em relação à alteridade que implica num movimento de aproximação e afastamento. Em seu texto Psicologia das Massas e Análise do Eu (1921), Freud utiliza a parábola dos porcos espinhos, de Schopenhauer, para mostrar este mesmo movimento nos porcos espinhos que se aproximam para tentar vencer o frio, mas afastando-se em seguida, por se espetarem:

Durante a era glacial, muitos animais morriam por causa do frio. Os porcos-espinhos juntavam-se em grupos, assim se agasalhavam e se protegiam mutuamente. Mas os espinhos de cada um feriam os companheiros mais próximos, justamente os que forneciam calor. E, por isso, tornavam a se afastar uns dos outros. Voltaram a morrer congelados e precisavam fazer uma escolha: desapareceriam da face da Terra ou aceitavam os espinhos do semelhante. Com sabedoria, decidiram voltar e ficar juntos. Aprenderam assim a conviver com as pequenas feridas que uma relação muito próxima podia causar, já que o mais importante era o calor do outro (Freud, 1984, p. 113).

Na verdade não podemos falar em alteridade, mas sim alteridades. O período da adolescência nos revela esta pluralidade que acompanha o percurso do sujeito. Freud nos ensina a respeito da variedade de outros: o outro-modelo; o outro-objeto; o outro-auxiliar e o outro-inimigo. A adolescência nos revela a dissimetria entre a alteridade na infância e na adolescência. A alteridade na infância pode contribuir para o assujeitamento da criança, enquanto que na adolescência é possível haver reviravoltas, malabarismos e, eventualmente, trocas são efetuadas no balanço dos trapézios onde estão o sujeito e o outro.

É preciso que os pais e os mestres aceitem o lugar desidealizado que o sujeito adolescente lhes confere. Só assim poderão contribuir para as importantes operações psíquicas da adolescência.

Recebido em 09 de novembro de 2012 Aprovado em 12 de abril de 2013

\section{Nota}

1 Freud refere-se a das Ding - a Coisa - para tratar do complexo do próximo e Lacan a utiliza como ponto de partida na elaboração do conceito de objeto $a$, o qual por não ter substância, corresponde à Coisa-em-si, no sentido kantiano. Das Ding situa-se do lado do real e não pode ser apreendida pelo simbólico. Por ser imutável, encontra-se sempre presente em todos os próximos que causam o desejo do sujeito. 


\section{Referências}

ALBERTI, Sonia. O Adolescente e o Outro. Rio de Janeiro: Jorge Zahar Ed., 2004. BETTO, Frei. Alteridade. Projeto Revoluções. Conferências, online, 2012. Disponível em: <http://www.freibetto.org/index.php/artigos/45-alteridade-freibetto>. Acesso em: 05 jun. 2012.

FREIRE, Paulo. Pedagogia do Oprimido. 9. ed. Rio de Janeiro: Paz e Terra, 1981. FREUD, Sigmund. La Afasia. Buenos Aires: Nueva Visión, 2004.

FREUD, Sigmund. Proyeto de Psicología. In: FREUD, Sigmund. Obras Completas de Sigmund Freud. 2. ed. Buenos Aires: Amorrortu, 1986. V. 1.

FREUD, Sigmund. Tres Ensayos de Teoria Sexual. In: FREUD, Sigmund. Obras Completas de Sigmund Freud. 2. ed. Buenos Aires: Amorrortu, 1978. V. 7.

FREUD, Sigmund. Escritos Sobre a Psicologia do Inconsciente. Rio de Janeiro: Imago, 2004.

FREUD, Sigmund. Psicologia de las Masas y Análisis del yo. In: FREUD, Sigmund. Obras Completas de Sigmund Freud. 2. ed. Buenos Aires: Amorrortu, 1984. V. 18.

FREUD, Sigmund. El Malestar en la Cultura. In: FREUD, Sigmund. Obras Completas de Sigmund Freud. 2. ed. Buenos Aires: Amorrortu, 1986. V. 21

FREUD, Sigmund. Novas Conferências Introdutórias sobre Psicanálise. Conferência XXXIV - Explicações, Aplicações e Orientações. In: Obras Completas de Sigmund Freud. Rio de Janeiro: Imago Editora, 1997. V. 22.

LACAN, Jacques. O Seminário, livro 1: os escritos técnicos de Freud. Rio de Janeiro: Jorge Zahar Ed., 1986.

LACAN, Jacques. O Seminário, livro 5: as formações do inconsciente. Rio de Janeiro: Jorge Zahar Ed., 1999.

LACAN, Jacques. O Seminário, livro 17: o avesso da psicanálise. Rio de Janeiro: Jorge Zahar Ed., 1992.

QUINET, Antonio. Os Outros em Lacan. Rio de Janeiro: Zahar, 2012.

SADALA, Gloria. O Sexo e o Mal-estar na Adolescência. In: ALBERTI, Sônia. A Sexualidade na Aurora do Século XXI. Rio de Janeiro: Companhia de Freud: Capes, 2008.

Eliane Gomes dos Santos é graduada em Comunicação Social pela PUC/RJ. Especialista em Documentos Oficiais e Pesquisa em Comunicação. Mestre em Psicanálise, Saúde e Sociedade da Universidade Veiga de Almeida. Coordenadora dos Cursos de Pós-Graduação Fora de Sede - UVA/RJ, Avaliadora e Membro da Comissão Própria de Avaliação da Universidade Veiga de Almeida, Rio de Janeiro, RJ - CPA/UVA.

E-mail: egomes@uva.br

Maria da Glória Schwab Sadala é psicanalista. Doutora pela UFRJ. Coordenadora do Curso de Mestrado em Psicanálise, Saúde e Sociedade e do Curso de Especialização em Teoria Psicanalítica e Prática Clínico-Institucional da Universidade Veiga de Almeida, Rio de Janeiro, RJ. Supervisora do SPA/ UVA. Professora e Supervisora do Curso de Especialização em Psicologia Clínica da PUC/RJ. Membro do Colegiado de FCCL-RJ.

E-mail: gloriasadala@uva.br 